\title{
Kidney and Liver Functions and Stress Oxidative Markers of Monosodium Glutamate-Induced Obese Rats
}

\author{
María del Carmen Contini*, Néstor Millen, Luisina Riera, Stella Mahieu \\ Laboratorio de Investigaciones Fisiológicas Experimentales (LIFE). Facultad de Bioquímica y Ciencias Biológicas. Universidad Nacional \\ del Litoral. Ciudad Universitaria. Paraje El Pozo. CC 242. Santa Fe. (3000). Argentina
}

\begin{abstract}
The purpose of the present study was to determine the function and oxidative status in kidney and liver using a model of obesity induced by neonatal treatment of rats with monosodium glutamate, and to investigate the association of these metabolic changes with antioxidant enzymes, oxidative stress and NO generation. Methods: neonate male Wistar rats were subcutaneously injected, with monosodium L-glutamate (MSG), at a dose of $4 \mathrm{~g} / \mathrm{kg}$ body weight at days 2, 4, 6, 8 and 10 of life. We evaluated: anthropometrical parameters and obesity markers, intravenous glucose and insulin tolerance tests, liver function, bile flow and pharmacokinetic parameters, biochemical and histological studies in renal and hepatic tissues, measurement of oxidative stress markers and histopathological examination. Results: glutathione decreased in kidney; glutathione peroxidase (GPx), glutathione reductase and superoxide dismutase (SOD) increased activities. These suggest that the oxidative defences of kidney reacts positively giving to such tissue more resistance against to the oxidative stress. There may be a ROS mediate inactivation of NO and as a result reduced renal plasma flow and glomerular filtration rate. In liver redox status induces decrease in SOD and increase in GPx activity. Changes in redox status would be responsible of the functional and histological alterations observed both in kidney and liver.
\end{abstract}

Keywords Monosodium Glutamate, Oxidative Stress, Obesity, Kidney, Liver

\section{Introduction}

Obesity is an increasing problem in several countries, leading to health problems. Several experimental models have been proposed in order to induce obesity in animals according to its etiology, some of which have been widely characterized. During the last decade, there has been increasing evidence that MSG-treated animals develop central obesity, altered glucose tolerance and hyperinsulinaemia, which may appear as early as 12 weeks[1],[2]. Aerobic exercise was able to improve the glucose intolerance, with greater tissue uptake of glucose in response to insulin[3], and this was associated with an improvement in the release of insulin from $\beta$-cells[4]. Hypothalamic obesity is frequently used and can be induced in the neonatal period through the systemic administration of monosodium glutamate (MSG)[3],[5]. This model shows chemical lesions in arcuate nucleus structure, which results in endocrine disorders, such as obesity and glucose intolerance, thus leading to experimental diabetes.

These lesions cause stunting of growth without any increase of food intake[6-9]. Moreover, it has been reported

* Corresponding author:

mcontini@fbcb.unl.edu.ar (María del Carmen Contini)

Published online at http://journal.sapub.org/fph

Copyright (C) 2012 Scientific \& Academic Publishing. All Rights Reserved voracity and impaired GH secretion induced by parenterally administered MSG[10]. It is well established that oxidative stress status is enhanced in the animal model of diet induced obesity[11-13] and in MSG treated rats[14]. Obesity and hypertension are risk factors for the development of chronic kidney disease, and it has been suggested that obesity, even in the absence of diabetes, contributes significantly to the development and progression of chronic kidney disease[15-17]. In tissues, antioxidant defence, mainly made up of glutathione (GSH) and antioxidant enzymes opposes the toxic actions of reactive oxygen species (ROS). The primary antioxidant enzymes responsible for protection from ROS are superoxide dismutase (SOD), catalase (CAT), and glutathione peroxidase (GPx). Thus, oxidative stress is present in case of an imbalance between ROS production and antioxidant defences. Studies in which rats were fed an antioxidant-deficient, pro-oxidant diet have demonstrated the significance of an adequate antioxidant defence in both normal and injured kidneys[18],[19]. Oxidant injury is now recognized as playing a key role in the pathophysiologic pathways of a wide variety of progressive clinical and experimental renal diseases[20]. Nitric oxide (NO), an important mediator of vascular tone and renal function, regulates glomerular, vascular, and tubular function in the kidney[21]. An increase in renal and vascular oxidative stress can be effectively counteracted by NO via its rapid inactivation of superoxide[22]. It is believed that any 
condition that leads to an increase in ROS production and/or a decrease in NO generation shifts the balance towards oxidative stress and influences renal and vascular function[23]. Thus, the major purpose of the present study was to determine the function and oxidative status in kidney and liver using a model of obesity induced by neonatal treatment of rats with MSG. We also investigated the association of these metabolic changes with antioxidant enzymes, oxidative stress and $\mathrm{NO}$ generation.

\section{Materials and Methods}

\subsection{Animals and Obesity}

Neonate male Wistar rats were subcutaneously injected, with monosodium L-glutamate (MSG), at a dose of $4 \mathrm{~g} / \mathrm{kg}$ body weight at days 2, 4, 6, 8 and 10 of life, while the other male group (Control rats) were injected with physiological saline[24-27]. The injection volume was $8 \mu \mathrm{l} / \mathrm{g}$ body weight. The pups were left with their own mothers and were weaned at $4 \mathrm{wk}$ of age. All animals were housed, under control conditions, in a 12-h light-dark cycle luminosity and temperature $\left(21 \pm 2^{\circ} \mathrm{C}\right)$. Animals were allowed free access to tap water and a standard diet containing approximately 130 $\mathrm{mmol} / \mathrm{kg}$ sodium, $160 \mathrm{mmol} / \mathrm{kg}$ potassium, $23 \%$ protein and $5 \%$ fat. The experimental protocol was approved by the Human and Animal Research Committee of the School of Biochemistry, University of Litoral, Santa Fe, Argentina.

\subsection{Anthropometrical Parameters and Obesity Markers}

Body weights (BW) and lengths (nose-tail and nose-anal) were measured at 4 weeks of age initially and then once a week up to 7 months of age. The body weight and body length were used to determine the following anthropometrical parameter: the Lee index[28][the cube root of body weight $(\mathrm{g})$ divided by the nose anal length $(\mathrm{cm})]$, employed as a predictor of obesity, was calculated at 4,5 , 6 ,and 7 months of age.

\subsection{Intravenous glucose tolerance test (IGTT)}

IGTT was performed in MSG-treated and untreated rats at seven months of age, under anesthesia by injection of pentobarbital $(50 \mathrm{mg} / \mathrm{kg}$ b.w., i.p.). After an overnight fasting of $8 \mathrm{~h}$, a glucose load $(1 \mathrm{~g} / \mathrm{kg}$ body weight $)$ was infused in the animals through femoral vein. Blood samples were obtained from a cut tip tail for glycemic determinations immediately before glucose load (zero time) and at 10, 20,30, 40,50 y $60 \mathrm{~min}$. Thereafter, the constant rate for plasma glucose disappearance $(\mathrm{Km})$ was calculated based on linear regression of the neperian logarithm of glucose concentrations.

\subsection{Insulin Tolerance Test (ITT)}

Seven months old MSG-treated and control rats, after an overnight fasting of $8 \mathrm{~h}$, underwent an intraperitoneal insulin tolerance test (1 U/kg body weight of insulin), and samples for blood glucose measurements were collected at 0 (basal), $5,10,15,20,25$ and 30 min after injection from a cut tip tail. There after, the rate constant for plasma glucose disappearance $(\mathrm{Km})$ was calculated by formula $0.693 /\left(\mathrm{t}_{1 / 2}\right)$. The plasma glucose $t_{1 / 2}$ was calculated from the slope of the least square analysis of the plasma glucose concentrations during the linear phase of decline[27].

\subsection{Experiments in Metabolic Cages}

After 7 months of age, rats $(\mathrm{n}=6$, each group) were housed in metabolic cages to determine urine volume and food and water intake. Animals received demineralized water and standard diet that contained $129 \mathrm{mmol} \mathrm{Na} / \mathrm{kg}$. Daily sodium balance was calculated as sodium intake minus sodium excretion. After two days of adaptation, daily water and sodium balance were measured during the last one day. Potassium, creatinine and protein excretion and urine osmolality were analysed in urine collected during the last 24 hours. Then twelve-hour urine samples were collected and were analysed NOx metabolites. To eliminate contamination of urine samples, animals received only water during the 12 $\mathrm{h}$ collection period. Then, another experiment was performed to assess the urinary concentration ability. Rats ( $\mathrm{n}=6$, each group) were deprived of food and water for 18 hours and then were given an im injection of 1- deamino -[8-D-arginine] - vasopressin (DDAVP, $1 \mathrm{nmol} / 100 \mathrm{~g}$ body weight; Ferring Pharmaceuticals), a V2 receptor-selective vasopressin agonist. Spontaneously voided urine was collected 120 minutes after DDAVP injection for osmolality determination.

\subsection{Renal Function Measurements}

At the end of the above experiment control $(n=6)$ and MSG-treated rats $(n=6)$ were anesthetized by injection of pentobarbital $(50 \mathrm{mg} / \mathrm{kg}$ b.w., i.p.) and were prepared for renal clearance studies as previously reported[29]. The femoral vein and the femoral artery were cannulated. The bladder was exposed through a small abdominal incision and cannulated with a catheter (internal diameter: $3 \mathrm{~mm}$ ) for urine collection. A solution containing inulin $(1 \mathrm{~g} / 100 \mathrm{ml})$, sodium $p$-aminohippurate (PAH, $0.3 \mathrm{~g} / 100 \mathrm{ml}$ ) and isotonic saline was infused through the femoral vein catheter at a rate of 1 $\mathrm{ml} / \mathrm{h} .100 \mathrm{~g}$ wb using a constant infusion pump (Sage Instruments, model 341-B-syringe pump). After equilibration for $60 \mathrm{~min}$, urine samples were obtained during two periods of $30 \mathrm{~min}$. Blood samples were obtained from the femoral artery at the midpoint of each collection period. Urinary volume was measured. Glomerular filtration rate (GFR) was determined by inulin clearance and renal plasma flow was estimated by PAH clearance. Creatinine, inulin, $\mathrm{PAH}$, sodium, potassium and osmolality were measured in serum and urine samples. Urea and aldosterone were determined in serum samples. Fractional excretion of water $\left(\mathrm{FEH}_{2} \mathrm{O}\right)$, sodium (FENa) and potassium (FEK) were calculated by conventional formulae.

\subsection{Liver Function Bile Flow and Pharmacokinetic Parameters}


Bile flow and biliary excretion of cholephilic xenobiotic (bromosulphophthalein - BSP) were determined by the ability of the hepatocyte to transport solutes. For this purpose, seven months old rats from both groups received a BSP injection $(6 \mathrm{mg} / 100 \mathrm{~g} w \mathrm{w}$, iv). Blood samples were collected every 2 min over a $30 \mathrm{~min}$ time period and bile samples were collected every $10 \mathrm{~min}$ over a $60 \mathrm{~min}$ time period. Plasma and bile BSP concentrations were determined spectrophotometrically at $580 \mathrm{~nm}$, after the addition of $0.5 \mathrm{M}$ $\mathrm{NaOH}$. The percentage of biliary BSP recovery was estimated by the percentage ratio between the dye excreted in bile samples throughout the experimental period and the amount of BSP injected. In vivo pharmacokinetic studies BSP decay were carried out to assess the fractional transfer rates for the transport of the dye from plasma to liver (hepatic uptake, $\mathrm{r}_{12}$ ), liver to plasma (sinusoidal efflux, $\mathrm{r}_{21}$ ) and liver to bile (canalicular excretion, $r_{3}$ ). For this purpose, the plasma dye concentration data, plotted against time were fitted by a least-squares curve-fitting technique to the bi-exponential equation, according to standard formulas for a bicompartmental open model[30].

\subsection{Biochemical and Histological Studies in Renal and Hepatic Tissues}

In another set of two different groups of rats (control and MSG treated), at seven months of age, ( $\mathrm{n}=6$ for each group) were fasted overnight (10-12 h) weighed and anesthetized by ip injection of sodium pentobarbital $(50 \mathrm{mg} / \mathrm{kg}$ b.w., ip). Blood was collected by cardiac puncture and kidneys and liver were removed. Kidney was weighed. One part was processed for histology, and the rest were frozen and stored in liquid nitrogen. Then, the epididymal and retroperitoneal fat pads were isolated and weighed to estimate obesity induced by MSG treatment. Triglyceride, total cholesterol, Aspartate aminotransferase (ASAT), alanine aminotransferase (ALAT) and alkaline phosphatase (ALP) were measured in plasma.

Different sets of renal cortex and liver samples were homogenized with a Polytron homogenizer in different buffers as follows: 1$)$ in buffered sucrose medium $(0.25 \mathrm{M}$ sucrose, $10 \mathrm{mM}$ Tris- $\mathrm{HCl},(\mathrm{pH}$ 7.0) for superoxide dismutase (SOD) activity measurement; 2) in $50 \mathrm{mM}$ phosphate buffer ( $\mathrm{pH} 7.0$ ) containing $1 \mathrm{mM}$ EDTA, for glutathione peroxidase (G-Px), glutathione reductase (GR) and catalase (CAT) activity measurements; 3 ) in cold $1,15 \%$ $\mathrm{KCl}$ for thiobarbituric acid reactive substances (TBARS) measurement; and 4) in cold 5\% trichloroacetic acid in 0.01 $\mathrm{M} \mathrm{HCl}$ for non-protein sulfhydryl (NPSH) pool (principally glutathione - GSH) measurement.

\subsection{Measurement of Oxidative Stress Markers}

SOD activity was assayed according to the method of Misra and Fridovich[31]. G-Px activity was determined according to the method of Lawrence and Burk[32]. GR activity was assayed according to the method of Horn[33] and CAT activity was determined following the method of
Aebi[34]. Determination of renal GSH was carried out in homogenates as described by Ellman[35]. TBARS was assayed according to the method of Okhawa et al.[36]. Protein concentration in renal homogenates was determined by the method of Lowry et al.[37] with bovine serum albumin as standard.

\subsection{Histopathological Examination}

Portions of the tissues from kidney and liver were used for histopathological examination. Tissues were fixed in $10 \%$ buffered formalin $(\mathrm{pH} 7,2)$ and dehydrated through a series of ethanol solutions, embedded in paraffin, and routinely processed for histological analysis. Sections of $5 \mu \mathrm{m}$ thickness were cut and stained with hematoxylin-eosin and PAS and examined by light microscopy.

\subsection{Analytical Methods}

Determination of creatinine in serum and urine, total cholesterol, triglycerides, and urea nitrogen (BUN), ASAT, ALAT and ALP concentrations were determined in plasma with an automatic analyser (Selectra-2, Vitalab). Plasma glucose concentration was determined by glucose oxidase kit. Serum and urine osmolality were determined using a vapor pressure osmometer (model $5100 \mathrm{C}$, Wescor). Sodium and potassium were determined by flame photometry. Aldosterone in serum was measured by RIA using a commercial kit (Coat-A-Count Aldosterone, DPC, Los Angeles, CA). Urinary protein excretion was measured by precipitation with 3\% sulphosalicylic acid[38]. NOx (nitrate and nitrite) metabolites detection kit was purchased from Cayman Chemical.

\subsection{Statistical Analysis}

Results are expressed as mean \pm S.E.M (standard error of the mean). Data were analysed using the one-way analysis of variance followed by Scheffe contrast. The 0.05 level of probability was used as the criterion of significance in all cases. The statistical analysis was made with SPSS - PASW Statistics 18.0.

\section{Results}

\subsection{Effects of MSG Neonatal Treatment in Anthropometrical Parameters and Fat Accumulation of Adult Rats}

Physiological parameters of the two groups of Wistar rats at the end of the study are presented in Table 1. Body weight did not differ significantly between the control and MSG-treated group at 7 months of age, and had almost the same weight gain. Nose anal length was significantly shorter in the MSG-treated groups than in control. The MSG-treated rats generally appeared shorter and stunted in growth compared with control rats. Thus the Lee Index and retroperitoneal and epididymal fat depositions were 
markedly higher in MSG-treated than control. Absolute and normalized kidney and liver weights were not significantly different among groups.

Table 1. Body Weight and Adiposity in Control and MSG rats after 7 months of age

\begin{tabular}{|c|c|c|}
\hline & $\mathrm{C} \mathrm{n}=6$ & MSG $\mathrm{n}=6$ \\
\hline Initial body weight (g) & $40.5 \pm 2.5$ & $41.2 \pm 1.9$ \\
\hline Body weight (g) & $478 \pm 18$ & $481 \pm 23$ \\
\hline Body weight gain (g) & $432 \pm 13$ & $440 \pm 20$ \\
\hline Nose-anal lenght (cm) & $26.0 \pm 0.31$ & $24.1 \pm 0.27^{*}$ \\
\hline Total lenght (cm) & $46.1 \pm 0.43$ & $42.2 \pm 0.76^{*}$ \\
\hline $\begin{array}{c}\text { Epididymal fat weight } \\
\text { (g/100 g bw) }\end{array}$ & $1.76 \pm 0.08$ & $3.47 \pm 0.15^{*}$ \\
\hline $\begin{array}{c}\text { Retroperitoneal fat weight } \\
\text { (g/100 g bw) }\end{array}$ & $1.57 \pm 0.04$ & $3.12 \pm 0.05^{*}$ \\
\hline Lee Index & $0.303 \pm 0.002$ & $0.316 \pm 0.002^{*}$ \\
\hline $\begin{array}{c}\text { Relative kidney weight } \\
\text { (g/100 g bw) }\end{array}$ & $0.73 \pm 0.03$ & $0.69 \pm 0.03$ \\
\hline $\begin{array}{c}\text { Relative liver weigth } \\
\text { (g/100 g bw) }\end{array}$ & $3.30 \pm 0.16$ & $3.50 \pm 0.25$ \\
\hline
\end{tabular}

Data are expressed as mean \pm SEM of 6 rats in each group. Groups: C: control rats; MSG: rats treated with MSG

* Statistically different from control values $(\mathrm{p}<0.05)$

\subsection{Effects of MSG neonatal treatment biochemical determinations, fasting plasma glucose, peripheral insulin resistance of adult rats}

As shown in Table 2 plasma total cholesterol and HDL cholesterol did not differ significantly among groups. Plasma triglycerides, fasting levels of glucose and ALAT were higher in MSG rats compared with controls.

Table 2. Effects of MSG-neonatal treatment in adult rats

\begin{tabular}{|c|c|c|}
\hline & $\mathrm{C} \mathrm{n}=6$ & MSG $\mathrm{n}=6$ \\
\hline Cholesterol total mg/dl & $86.3 \pm 2.5$ & $73.9 \pm 4.3$ \\
\hline HDL-C mg/dl & $41.7 \pm 6.2$ & $41.0 \pm 3.6$ \\
\hline Triglycerides mg/dl & $63.3 \pm 5.2$ & $122.7 \pm 18.5^{*}$ \\
\hline Plasma glucose mg/dl & $0.91 \pm 0.03$ & $1.13 \pm 0.04^{*}$ \\
\hline $\begin{array}{c}\text { Alanine aminotransferase } \\
\text { (ALAT) U/l }\end{array}$ & $34.0 \pm 3.6$ & $53.7 \pm 5.8^{*}$ \\
\hline $\begin{array}{c}\text { Aspartate aminotransferase } \\
\text { (ASAT) U/l }\end{array}$ & $99.7 \pm 2.2$ & $109.3 \pm 1.8$ \\
\hline $\begin{array}{c}\text { Alkaline phosphatase (ALP) } \\
\text { U/l }\end{array}$ & $204 \pm 10$ & $210 \pm 12$ \\
\hline
\end{tabular}

Data are expressed as mean \pm SEM of 6 rats in each group. Groups: C: control rats; MSG: rats treated with MSG.

* Statistically different from control values $(\mathrm{p}<0.05)$

Intravenous glucose tolerance test showed, at seven months evidence of glucose intolerance in MSG treated rats when compared to control. MSG-rats presented a lower plasma glucose disappearance rates (kIGTT- \% $\mathrm{min}^{-1}$ ). Control: $1.40 \pm 0.008$; MSG: $0.87 \pm 0.007 *$.
MSG-rats were insulin resistant when compared to control rats, as expressed by their lower plasma glucose disappearance rates measured by the insulin tolerance test. MSG-rats showed a reduction of glucose disappearance rates (k ITT-\% $\mathrm{min}^{-1}$ ) up to $34 \%$. Control: $2.35 \pm 0.01$; MSG: $0.85 \pm 0.01 *$.

Lee index negatively correlated with $\mathrm{kITT}(\mathrm{r}=-0.88, \mathrm{p}=$ $0.0001)$ and positively correlated with triglyceride $(r=0.61$ $\mathrm{p}=0.016$ ).

\subsection{Effects of MSG-neonatal administration on renal water excretion and on the sodium balance in adults rats at 7 months of age}

The food intake was almost the same in MSG-rats and the controls (g/day) (Control: 18.2 \pm 1.3 ; MSG: $18.6 \pm 1.5$ ). Daily water intake was higher in MSG $\left(33.6 \pm 2.6^{*}\right)$ rats than in Control $(26.3 \pm 2.3, \mathrm{p}<0.05)$, however, daily urine excretion, daily sodium intake and daily sodium excretion were similar in both groups.

Neonatal MSG treatment increased the degree of proteinuria, which was significantly elevated compared with the control group. Control: $12 \pm 2.2$; MSG: $21 \pm 0.8 * \mathrm{mg} / \mathrm{day}$, $\mathrm{p}<0.05$ at seven months of life. Urinary excretion of NOx metabolites (nitrates + nitrites) was significantly lower in the MSG-treated rats than in control group: Control: $1721.7 \pm$ 124.8; MSG: $1064.4 \pm 122.5^{*} \mathrm{nmol} / 12 \mathrm{~h}, \mathrm{p}<0.05$.

Urinary osmolarity were measured in both groups after 18 hours of water deprivation and administration of Desmopressin to asses concentrating capacity. MSG treatment had no effect on urinary concentrating capacity. (Control: $2219 \pm 68$; MSG: $2338 \pm 60, \mathrm{mOs} / \mathrm{Kg}$ ).

\subsection{Effects of MSG-neonatal Administration on Renal Function, Using Clearance Techniques}

Glomerular filtration rate (GFR), estimated by inulin clearance and cortical renal plasma flow, estimated by PAH clearance $\left(\mathrm{Cl}_{\mathrm{PAH}}\right)$, were measured by conventional clearance techniques (Table 3). Both GFR and $\mathrm{Cl}$ PAH were significantly reduced in MSG rats, without change in filtration fraction (FF). The fractional excretion of sodium, potassium and water were not different between the two groups of rats.

Neither the levels of urea, creatinine, sodium, potassium, osmolality nor aldosterone in serum were different between both groups (Aldosterone: Control $\mathrm{n}=6,187 \pm 28.5$; $\mathrm{MSG} \mathrm{n}=$ $6,182 \pm 34.5)$.

Table 3. Renal functional parameters at the seven months of age in control and MSG treated rats measured by clearance techniques

\begin{tabular}{|c|c|c|c|}
\hline & $\begin{array}{c}\text { GFR } \\
(\mathrm{ml} / \text { min g kidney) }\end{array}$ & $\begin{array}{c}\text { ClPAH (ml/ min g } \\
\text { kidney) }\end{array}$ & FF \\
\hline Control $(\mathrm{n}=6)$ & $0.88 \pm 0.09$ & $3.94 \pm 0.32$ & $0.21 \pm 0.01$ \\
\hline MSG-rats $(\mathrm{n}=6)$ & $0.62 \pm 0.09^{*}$ & $3.06 \pm 0.12^{*}$ & $0.20 \pm 0.01$ \\
\hline
\end{tabular}

Data are expressed as mean \pm S.E.M. Groups: C: control rats; MSG: rats treated with MSG. GFR: Glomerular filtration rate; Cl PAH: p-aminohippurate clearance; FF filtration fraction

* Statistically different from control values $(\mathrm{p}<0.05)$ 
Table 4. Antioxidant enzyme ratios in kidney and liver tissue of rats treated with MSG

\begin{tabular}{|c|c|c|c|c|}
\hline & \multicolumn{2}{|c|}{ Kidney } & \multicolumn{2}{c|}{ Liver } \\
\hline & Control rat (n=6) & MSG rat (n=6) & $\begin{array}{c}\text { Control rat } \\
(\mathrm{n}=6)\end{array}$ & MSG rat (n=6) \\
\hline GR/GPx & $0.41 \pm 0.09$ & $0.50 \pm 0.09$ & $0.28 \pm 0.02$ & $0.29 \pm 0.01$ \\
\hline GPx/SOD & $3.53 \pm 0.12$ & $3.15 \pm 0.23$ & $5.30 \pm 1.15$ & $8.4 \pm 1.95^{*}$ \\
\hline CAT/SOD & $5.24 \pm 0.21$ & $4.0 \pm 0.30^{*}$ & $4.9 \pm 0.98$ & $8.2 \pm 1.25^{*}$ \\
\hline
\end{tabular}

Data are expressed as mean \pm SEM. * Statistically different from control values $\mathrm{p}<0.05$
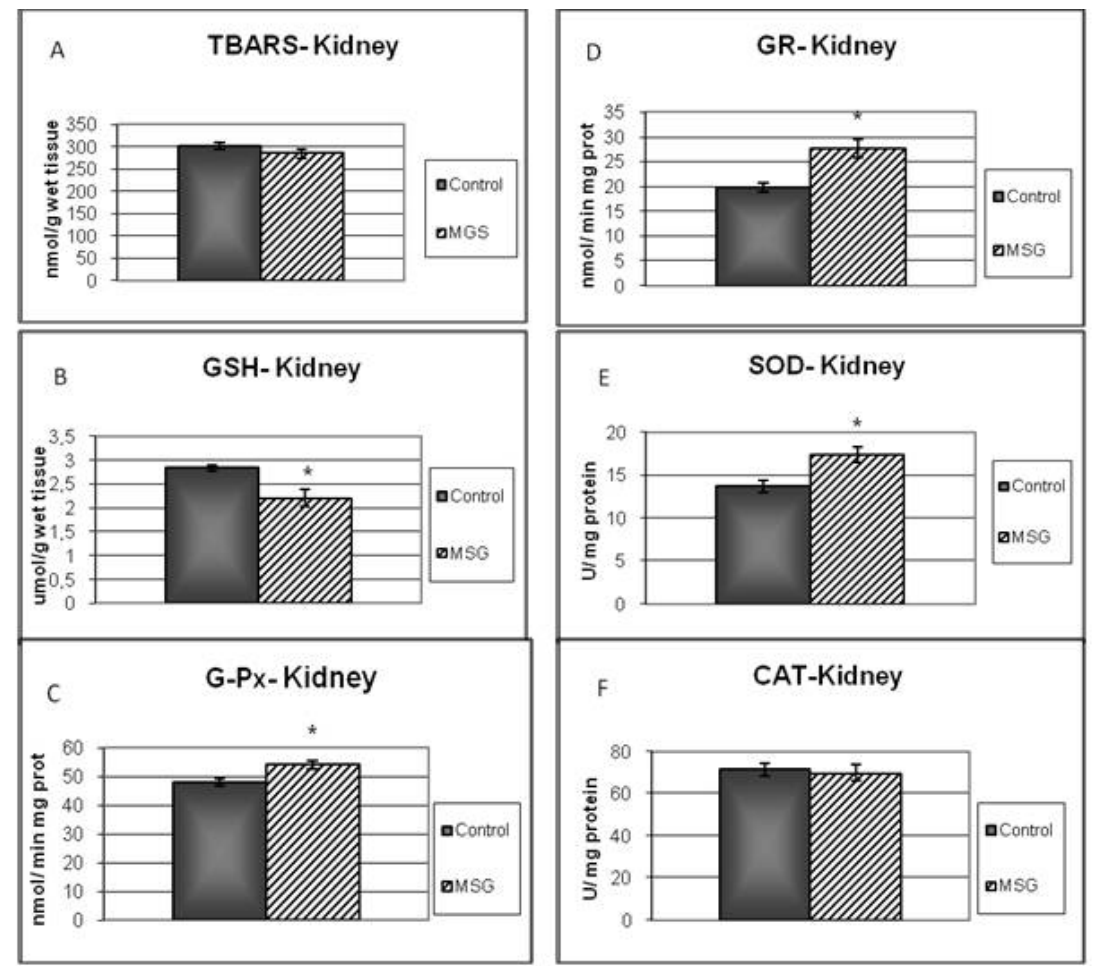

Figure 1. Oxidative stress markers in kidney. Superoxide dismutase (SOD), catalase (CAT), glutathione peroxidase (G-Px) glutathione (GSH), glutathione reductase (GR) and thiobarbituric acid reactive substances (TBARS). Data are expressed as mean \pm SEM of 6 rats in each group. Groups: C: control rats; MSG: rats treated with MSG. * statistically different from control values $(p<0.05)$

\subsection{Effects of MSG-neonatal administration on bile flow and biliary excretion of BSP}

No difference was observed in the bile flow and plasma clearance of BSP between both groups, which were accompanied by an unchanged fractional rate of hepatic BSF uptake and fractional rate of the dye biliary excretion.

\subsubsection{Lipid peroxidation and cellular defences enzymes in kidney}

TBARS levels were measured as an index of malondialdehyde production and hence lipid peroxidation. Results of TBARS did not show any difference between groups (Fig. 1-A). Further, evaluations of enzymes and chemicals associated with the antioxidant system were done. Fig. 1-B shows that GSH levels were significantly decreased in MSG-group compared with the control. On the other hand, MSG treated rats increased significantly the G-Px and GR activities (Fig 1-C; 1-D). The kidney activity of SOD was higher (Fig 1-E) and there was no change in CAT activity in
MSG-rats (Fig 1-F). The GR/GPx and GPx/SOD ratios did not show any difference between groups, but CAT/SOD ratio decreased. (Table 4).

\subsubsection{Lipid peroxidation and cellular defences enzymes in liver}

There were not changes in neither TBARS or GSH level in liver on MSG-rats (Fig 2-A and 2-B). MSG treated rats increased G-Px activity, with a decreased SOD activity (Fig 2-C, 2-D). Examination of other enzyme associated with oxidative stress (GR, and CAT) did not show any difference between groups (Fig. 2-E, 2-F). The GR/GPx ratio showed not difference when compared to the control group. The GPx/SOD and CAT/SOD ratios increased significantly respect to control group (Table 4).

\subsection{Histopathological Examination}

Staining procedures for light microscopy using haematoxylin and eosin (H\&E) and PAS (periodic acid Schiff) were carried out on $5-\mu \mathrm{m}$-thick tissue sections. 


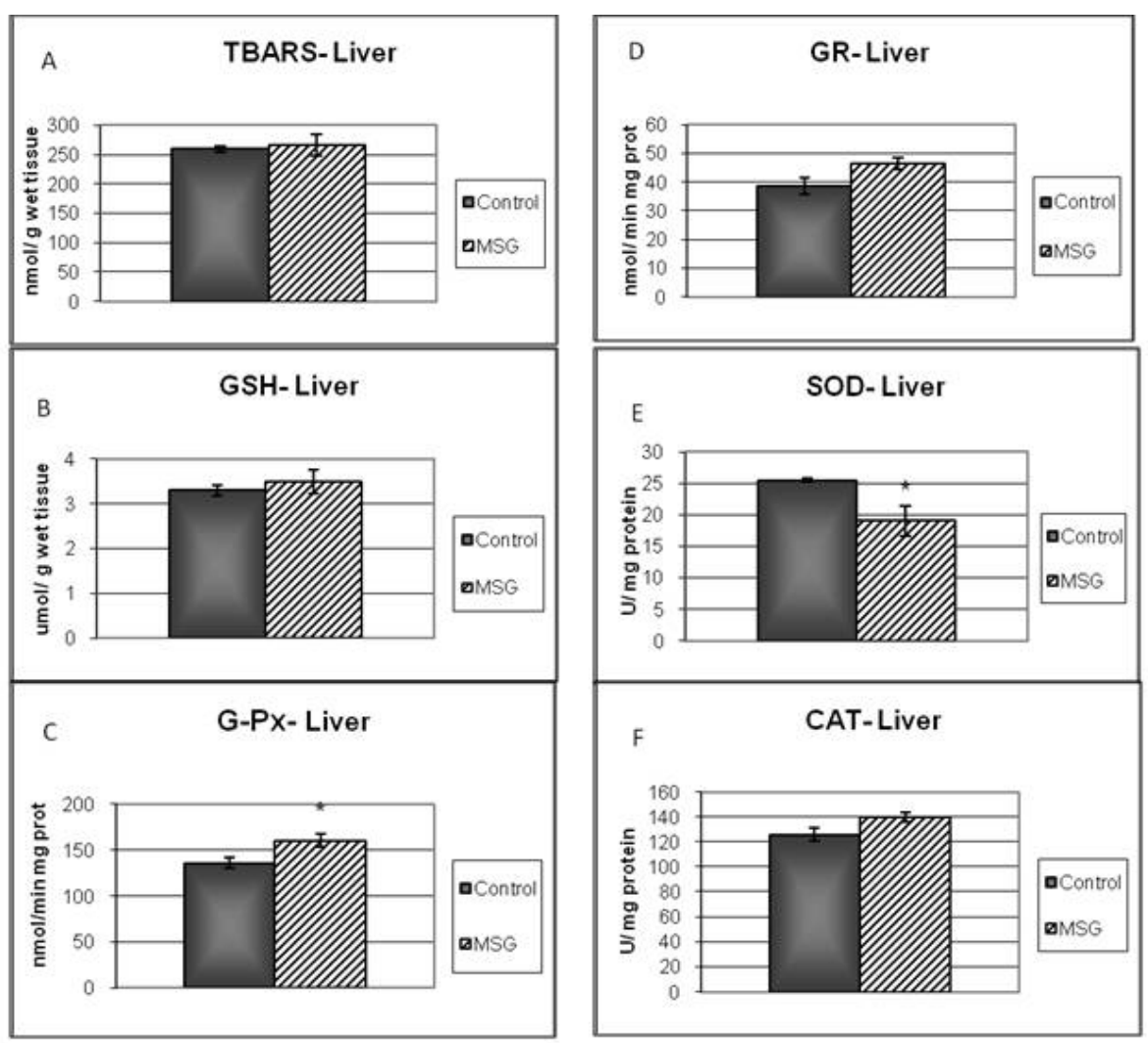

Figure 2. Oxidative stress markers in liver. Superoxide dismutase (SOD), catalase (CAT), glutathione peroxidase (G-Px) glutathione (GSH),glutathione reductase (GR) and thiobarbituric acid reactive substances (TBARS). Data are expressed as mean \pm SEM of 6 rats in each group. Groups: C: control rats; MSG: rats treated with MSG. * statistically different from control values $(\mathrm{p}<0.05)$

is.
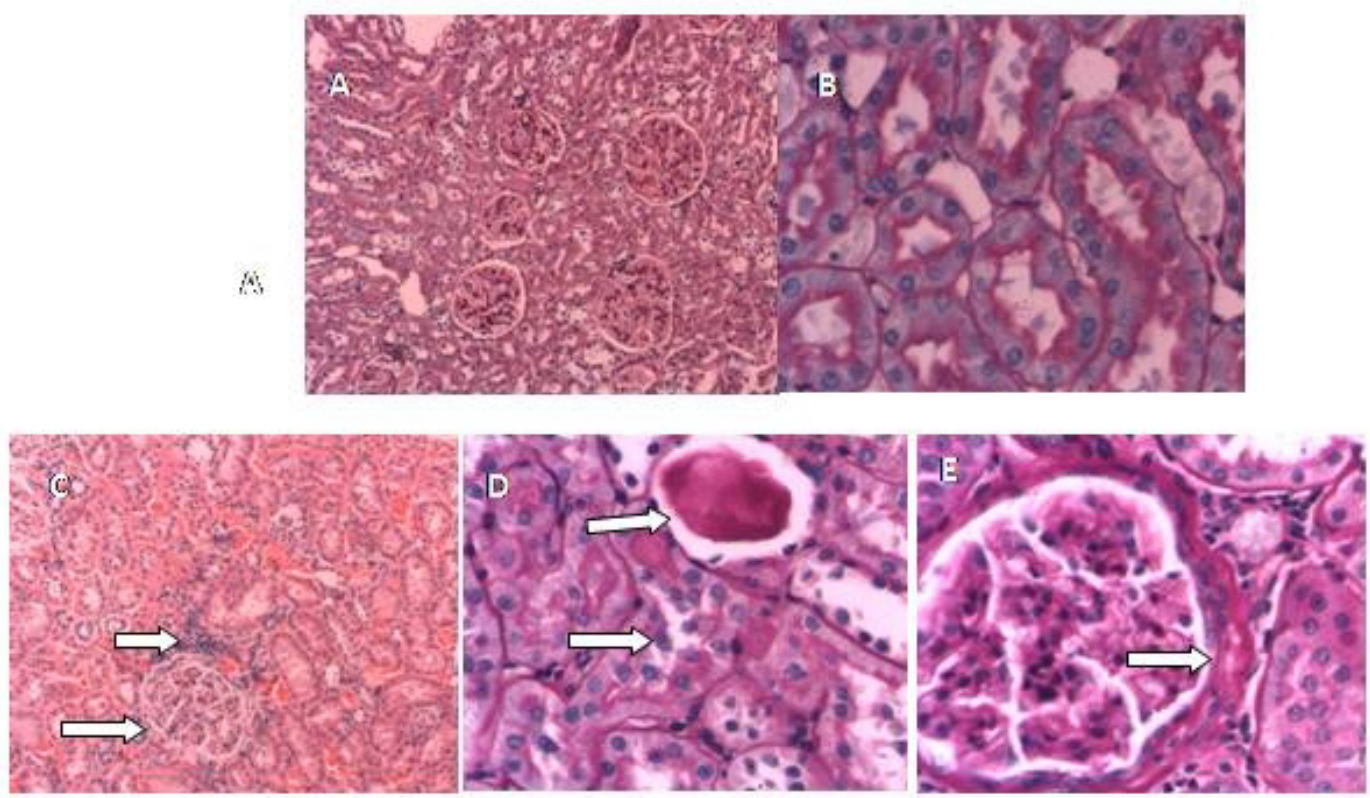

Figure 3. Renal morphology. Control rats: A (H\&E $10 \mathrm{x}$ ) and B (PAS $40 \mathrm{x})$. MSG rats: C (H\&E $10 \mathrm{x}$ ) focal interstitial inflammation and thickened capsule, D(PAS $40 \mathrm{x}$ ) cast hyaline and tubular damage and E(PAS $40 \mathrm{x}$ ) thickened capsule 

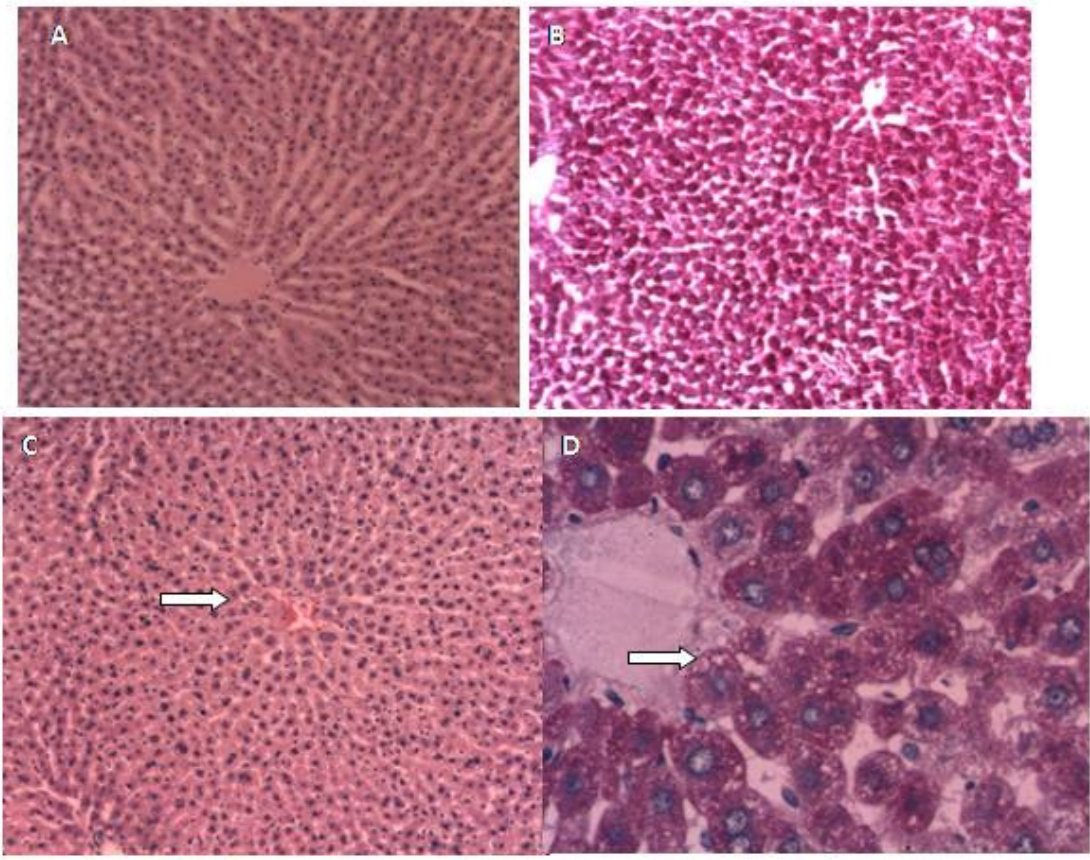

Figure 4. Liver morphology. Control rats: A (H\&E 10x) and B (PAS $10 \mathrm{x}$ ). MSG rats: C (H\&E 10x) and D (PAS $40 \mathrm{x})$ steatosis

At 7 months the rats that received neonatal treatment with MSG show degenerative changes in proximal tubules with vacuolated cytoplasm without displacement of nuclei and brush border preserved. In the lumen of the collector and distal tubules, cylinders and protein precipitate are observed. There was focal interstitial inflammation. The glomerule show thickening of the membrane. (Fig. 3)

In the liver lobular structures, trabecular and portals are preserved, but there is steatosis characterized by cytoplasmic vacuoles fat throughout the liver lobule (Fig. 4)

\section{Conclusions}

The purpose of this study was to establish the relationship between the renal and liver damage found in rat model obesity induced by neonatal treatment with MSG, and the alterations found in the antioxidant enzymes levels, as well as TBARS and GSH.

Male Wistar rats treatment with neonatal MSG induces obesity in adult rats with impaired glucose tolerance, increasing levels of plasmatic glucose, resistance to insulin and hypertriglyceridemia. These results confirm the ones obtained from different studies, even though they do not always show hyperglycemia[39].

Metabolic abnormalities such as hypertriglyceridemia and insulin resistance, examined in ITT, were related to the levels of obesity analysed according to Lee index, which were also proved by other authors[40]. This last effect can be related to the alteration of the peripheral tissue glucose uptake as there is evidence of patients with peripheral resistance that require high doses of insulin during ITT in order to reduce the levels of glycemia[41].
Treated rats reduced their size as well as nose-to-anus length and total length, without major variations in the weight of the organs which have been studied at seven months of age. Other authors have reported that certain organs have reduced their size[42].

Obesity is associated with hemodynamic changes, among others, with an increase of the regional blood flow, the cardiac output and blood pressure[43]. Moreover, in the metabolic syndrome an endothelial dysfunction has been descripted with decrease in the synthesis and release of vasodilating agents and increase of vasoconstrictors[44].

Our results show that MSG neonatal treatment, at seven months of age, decreased both glomerular filtration rate as renal plasma flow, without changes in the filtration fraction or the fractional excretion of sodium and water. Such changes, the urinary reduction excretion of $\mathrm{NO}$ and the presence of proteinuria, would be indicating a compromise of the renal function. This result agrees with studies released with obese Zuker rats that showed decreased creatinine clearance and high proteinuria values[11].

NO induces vasodilatation in renal arterioles, thus contributing to renal function. In MSG rats, NO reduction could be responsible for the decrease observed in both, glomerular filtration rate and renal plasma flow.

Obesity is associated with endothelial dysfunction due to ROS-mediated inactivation of $\mathrm{NO}[45][46]$. Increased generation of reactive oxygen species leads to NO inactivation. Consequently, NOx urinary excretion decreases because NO is sequestered in tissues rather than metabolized. NOx urinary excretion is reduced in several animal models of experimental hypertension associated with oxidative stress, such as lead intoxication[47], 5/6 nephrectomy in the rat[48], and glutathione depletion[49]. The oxidative stress is 
a risk factor for the renal injury and it is associated with the development and progression of the albuminuria.

In the tissues, the oxidative stress will be present in case of an imbalance between the productions of ROS and the antioxidant defences. Such increase was observed in obese rats[11] and in rats with hypercaloric diets treated with MSG[14]. SOD catalyzes the dismutation of the superoxide radical $\left(\mathrm{O}_{2}{ }^{-\cdot}\right)$ to oxygen peroxide $\left(\mathrm{H}_{2} \mathrm{O}_{2}\right)$ and it protects the organs from the $\mathrm{O}_{2}{ }^{-}$- damage. G-Px catalyzes the reduction $\mathrm{H}_{2} \mathrm{O}_{2}$ in water[50]. In turn, CAT, another important antioxidant metalloenzyme, takes part in the conversion of oxygen peroxide in water. Even though we have not proved an increase in the lipid peroxidation levels in renal tissue, the obesity induced by MSG altered the homeostasis of GSH with a reduction of its levels, which was accompanied by an increase in G-Px and GR activities. The depletion of renal GSH (22\%) suggests that obesity could be a contributing factor to the renal injury degree. G-Px, GR and SOD increase suggests that the kidney oxidative defences react positively giving more resistance to such tissue against the oxidative stress. Antioxidant enzymes activity increase and the possible increase of GSH turnover, even though their levels were diminished, they would keep a balance between the influence of ROS and the kidney oxidative defences. The increase of ROS would be balanced by the increase of the antioxidant enzymes activity, as indicated by the absence of changes in the G-Px/SOD and GR/G-Px relation. The degenerative changes and inflammatory reactivity observed in renal tissue might be related to oxidative stress.

Obesity is also an important risk factor for developing dyslipidemia and fatty liver. In MSG-rats, livers exhibit significant steatosis without a great inflammation, which was accompanied with hypertriglyceridemia. Only serum ASAT levels were significantly increased. This research agrees with the work in mice after 6 months of treatment of Nakanishi[51], he also observed the presence of neutrophils aggregation into the lobes and portal inflammation.

Bile secretion from the liver has a pivotal physiological role as an excretory route for endo and xenobiotics. To determine possible alterations in these transport systems, we evaluated the hepatic handling of the model organic anion $\mathrm{BSP}$, a relatively non-toxic organic anion that is widely used as an indicator of the liver function. In seven-month-old MSG rats, changes have not been observed in bile flow or pharmacokinetic parameters. MSG group contrast with the obese Zucker rat (a model of insulin resistance and obesity) which exhibit an impaired bile secretory function in fatty liver with significant functional and molecular alterations consistent with mild cholestasis[52].

Surprisingly, at the liver level in MSG rats, no increase was observed in the LPO; besides, we found that GSH level was almost normalized. However, superoxide dismutase activity was decreased whereas glutathione peroxidase was increased. This decrease in SOD/GPx ratio favors $\mathrm{O}_{2}{ }^{-}$. formation (decomposed by SOD) rather than $\mathrm{H}_{2} \mathrm{O}_{2}$ (formed by SOD and decomposed by GPx). It has been suggested that these alterations in antioxidant enzymes may limit oxidative damage because $\mathrm{O}_{2}^{-}$has a shorter half-life, is less membrane-permeable, and thus less harmful than $\mathrm{H}_{2} \mathrm{O}_{2} \cdot[53]$. Moreover CAT/SOD would indicate that the liver is efficient in converting $\mathrm{H}_{2} \mathrm{O}_{2}$ into $\mathrm{H}_{2} \mathrm{O}$ and singlet oxygen.

In conclusion, we have demonstrated that in obese rat model induced by monosodium glutamate neonatal treatment, GSH decreased in kidney, and no change in liver. The increase of G-Px, GR and SOD activities suggests that the oxidative defences of kidney reacts positively giving to such tissue more resistance against to the oxidative stress. Moreover there may be a ROS mediate inactivation of NO and as a result reduced renal plasma flow and glomerular filtration rate. In liver redox status induces decrease in SOD and increase in GPx activity. Changes in redox status would be responsible of the functional alterations observed both in kidney and liver.

\section{ACKNOWLEDGEMENTS}

This work was supported by grants from Universidad Nacional del Litoral, Argentina, CAI+D program.

\section{REFERENCES}

[1] Hirata AE, Andrade IS, Vaskevicius P, Dolnikoff MS. "Monosodium glutamate (MSG) obese rats develop glucose intolerance and insulin resistance to peripheral glucose uptake”. Braz JMed Biol Res 30, 671- 674. 1997.

[2] Ribeiro EB, do Nascimento CM, Andrade IS, Hirata AE, Dolnikoff MS. "Hormonal and metabolic adaptations to fasting in monosodium glutamate-obese rats". J Comp Physiol[B] 167, 430-437. 1997.

[3] De Mello MA, Souza T, Braga LR, Santos W, Ribeiro IA, Gobatto CA. "Glucose tolerance and insulin action in monosodium glutamate (MSG) obese exercise-trained rats". Physiology, Chemical, Physical \& Medicine 33, 63-71. 2001.

[4] De Souza CT, Nunes WM, Gobatto CA \& de Mello MA. "Insulin secretion in monosodium glutamate (MSG) obese rats submitted to aerobic exercise training". Physiol Chem Phys Med NMR 35, 43-53. 2003.

[5] Sukhanov SN, Andrade IS, Dolnikoff MS, Ferreira A. "Neonatal monosodium glutamate treatment alters rat intestinal muscle reactivity to some agonists". European Journal of Pharmacology 386 (2-3), 247-252. 1999.

[6] Oleney J W. "Brain lesions, obesity and other disturbances in mice treated with monosodium glutamate". Science.164: 719-21. 1969.

[7] Tanaka K, Shimada M, Nakao K, Kusuniki T. "Hypothalamic lesion induced by injection of monosodium glutamate in sucking period and subsequent development of obesity". Exp Neurol. 62:191-9. 1978.

[8] Burde RM, Schainker B, Kayes J. "Acute effect of oral and subcutaneous administration of monosodium glutamate on the arcuate nucleus of the hypothalamus in mice and rats". Nature. 233:58-60. 1971. 
[9] Sanabria ERG, Pereira MFS, Dolninkoff MS, Andrade IS, Ferreira AT, Cavalheiro EA. "Deficit in hippocampal long-term potentiation in monosodium glutamate-treated rats". Brain Research Bulletin 59, 47-51. 2002.

[10] Hermanussen M, Garcia AP, Sunder M, Voigt M, Salazar V, Tresguerres JA. "Obesity, voracity and short stature: the impact of glutamate on the regulation of apetite". Eur J Clin Nutr 60 (1): 25-31. 2006.

[11] Poirier B, Lannaud-Bournoville M, Conti M, Bazin R, Michel $\mathrm{O}$, Bariety J, Chevalier J, Myara I. "Oxidative stress occurs in absence of hyperglycaemia and inflammation in the onset of kidney lesions in normotensive obese rats". Nephrol Dial Transplant 15:467-476. 2000.

[12] Dobrian AD, Davies MJ, Schriver SD, Lauterio TJ, Prewitt RL. "Oxidative stress in a rat model of obesity-induced hypertension". 37: 554-560. 2001.

[13] Noeman SA, Haamode HE and Baalash AA. "Biochemical study of oxidant stress markers in the liver, kidney and heart of high fat diet induced obesity in rats". Diabetol Metab Syndr 3:17. 2011

[14] Diniz YS, Fernandes A, Campos KE, Mani F, Ribas BO, Novelli ELB. "Toxicity of hypercaloric diet and monosodium glutamate: oxidative stress and metabolic shifting in hepatic tissue". Food and Chemical Toxicology 42:313-319. 2004.

[15] Hall JE, Crook ED, Jones DW, Wofford MR, Dubbert PM. "Mechanisms of obesity-associated cardiovascular and renal disease". Am J Med Sci 324: 127-137. 2002.

[16] Kramer H, Luke A, Bidani A, Cao G, Cooper R, McGee D. "Obesity and prevalent and incident CKD: the Hypertension Detection and Follow- Up Program". Am J Kidney Dis 46: 587-594. 2005

[17] Griffin KA, Kramer H, Bidani AK. "Adverse renal consequences of obesity". Am J Physiol Renal Physiol 294: F685-F696. 2008.

[18] Nath KA, Salahudeen AK. "Induction of renal growth and injury in the intact rat kidney by dietary deficiency of antioxidants". J Clin Invest 86: 1179-1192. 1990.

[19] Nath KA, Paller MS. "Dietary deficiency of antioxidants exacerbates ischemic injury in the rat kidney". Kidney Int 38: 1109-1117. 1990.

[20] Haugen E, Nath K. "The involvement of oxidative stress in the progression of renal injury". Blood Purif 17: 58-65. 1999.

[21] Kone BC, Baylis C. "Biosynthesis and homeostatic roles of nitric oxide in the normal kidney". Am J Physiol Renal Physiol 272: F561-F578. 1997.

[22] Wilcox CS. "Oxidative stress and nitric oxide deficiency in the kidney: a critical link to hypertension?" Am J Physiol Regul Integr Comp Physiol 289:R913-R935. 2005.

[23] Wilcox CS, Pearlman A. "Chemistry and antihypertensive effects of tempol and other nitroxides". Pharmacol Rev. 60:418-469. 2008.

[24] Otoya, R.E., Seltzer, A.M., Donoso, A.O. "Decrease of (+)-3-[125I]MK- 801 binding to NMDA brain receptors revealed at puberty in rats treated neonatally with monosodium glutamate". Development Brain Research 95, 149-156. 1996.
[25] Cattaneo, L., Colonna, V.G., Zoli, M., Muller, E.E., Cocchi, D. "Hypothalamo-pituitary-IGF-1 axis in female ratsmade obese by overfeeding”. Life Sciences 61 (9), 881-889. 1997.

[26] Sanabria ERG, Pereira MFS, Dolninkoff MS, Andrade IS, Ferreira AT, Cavalheiro EA. "Deficit in hippocampal long-term potentiation in monosodium glutamate-treated rats”. Brain Research Bulletin 59, 47-51. 2002.

[27] Hirata, A.E., Alvarez-Rojas, F., Carvalheira, J.B., Carvalho, C.R., Dolnikoff, M.S., Abdalla Saad, M.J. "Modulation of IR/PTP1B interaction and downstream signaling in insulin sensitive tissues of MSG-rats”. Life Sci. 73, 1369-1381. 2003.

[28] Bernardis LL. "Prediction of carcass fat, water and lean body mass from Lee's nutritive ratio in rats with hypothalamic obesity". Experientia 26,789-90. 1970.

[29] Mahieu, S., Calvo, M.L. "Effect of chronic poisoning with aluminum on the renal handling of phosphate in the rat". Toxicol. Lett. 94, 47-56. 1998.

[30] González, M.A., Roma, M.G., Bernal, C.A., Alvarez, M.L. and Carrillo, M.C. "Biliary secretory function in rats chronically intoxicated with aluminium". Toxicol. Sci., 79, 189. 2004.

[31] Misra H and Fridovich I. "The role of superoxide anion in the autoxidation of epinephrine and a simple assay for superoxide dismutase". J Biol Chem.247, 3171-3175. 1972.

[32] Lawrence RA and Burk RF. "Glutathione peroxidase activity in selenion-deficient rat liver". Biochem. Biophys. Res. Commun. 71: 952-958. 1976.

[33] Horn HD. Glutathione reductase. In: Bergmeyer, H.U. ed. Methods of Enzimatic Analysis. Weniheim. Germany. Verlag Chemie. 1982.

[34] Aebi HE. Catalase. In: Bergmeyer, HU.ed. Methods of Enzimatic Analysis. Weniheim. Germany: Verlag Chemie. 3: 273-286. 1982.

[35] Ellman GL. Tissue sulphydryls group. Arch. Biochem. Biophys. 82: 70-73. 1959.

[36] Ohkawa H, Ohishi N, Yagi K. Assay of lipid peroxides in animal tissues by thiobarbituric acid reaction. Anal. Biochem. 95: 351-357. 1979.

[37] Lowry OH, Rosebrough NJ, Farr AL, Randall RJ. "Protein measurement with the Folin phenol reagent". J. Biol. Chem. 193: 265-275. 1951

[38] Bradley M, Schumann GB \&Ward PCJ. Examination of urine. In Clinical Diagnosis and Management by Laboratory Methods, 16th edn, ed. Henry JB, pp. 559-634.W. B. 1979.

[39] Macho, L., Fickova, M., Jezova, Zorad, S. "Late effects of postnatal administration of monosodium glutamate on insulin action in adult rats". Physiol. Res. 49 (Suppl 1), S79-S85. 2000 .

[40] Iwase M, Yamamote M, Iino K, Ichikawa K, Shinohara N, Yoshinari M, Fujishima M. "Obesity induced by neonatal monosodium glutamate treatment in spontaneously hypertensive rats: an animal model of multiple risk factors". Hypertens Res, 21:1-6. 1998.

[41] Goldfine, A.B., Moses, A.C. Syndromes of extreme insulin resistance, In: Kahn, C.R.,Weir, G.C., King, G.L., Jacobson, A.M., Moses, A.C., Smith, R.J. (Eds.), Jolin's Diabetes 
mellitus, fourteenth ed. Lippincott Williams \& Wilkins, Philadelphia, pp. 493-504. 2005.

[42] Morrison J F B, Shehab S, Sheen R, Dhanasekaran S, Shaffiullah M, Mensah-Brown E. "Sensory and autonomic nerve changes in the monosodium glutamate-treated rat: a model of type II diabetes". Exp Physiol 93. 2: 213-222. 2007.

[43] Hall, JE. "The kidney, hypertension and obesity". Hypertension. 41 (2) 265-633. 2003.

[44] Perez I, El Hafide M, Zamora Gonzalez J, Infante O, Chavira $\mathrm{R}$, Baños G. "Modulation of aortic vascular reactivity by sex hormones in a male rat model of metabolic syndrome". Life Sc 80:2170-2180. 2007.

[45] Reil, T.D., Barnard, R.J., Kashyap, V.S., Roberts, C.K., Gelabert, H.A. "Diet-induced changes in endothelial-dependent relaxation of the rat aorta". Journal of Surgical Research 85, 96-100. 1999.

[46] Roberts, C.K., Vaziri, N.D., Wang, X.Q., Barnard, R.J. "Enhanced NO inactivation and hypertension induced by a high in fat, refined-carbohydrate diet". Hypertension 36, 423-429. 2000

[47] Vaziri, N.D., Ding, Y., Ni, Z., Gonick, H.C. "Altered nitric oxide metabolism and increased oxygen free radical activity in lead-induced hypertension: effect of lazaroid therapy". Kidney International 52, 1042-1046. 1997.
[48] Vaziri, N.D., Oveisi, F., Ding, Y. "Role of increased oxygen free radical activity in the pathogenesis of uremic hypertension”. Kidney International 53, 1748-1754. 1998

[49] Vaziri, N.D., Wang, X.Q., Oveisi, F., Rad, B. "Induction of oxidative stress by glutathione depletion causes severe hypertension in normal rats". Hypertension 36, 142-146. 2000.

[50] Abuja, P.M., Albertini, R. "Methods for monitoring oxidative stress, lipid peroxidation and oxidation resistance of lipoproteins". Clinical Chimica Acta 306, 1-17. 2001.

[51] Nakanishi Y, Tsuneyama K, Makoto Fujimoto M, Salunga TL, Nomoto K, An J , Takano Y ,Iizuka S , Nagata M , Suzuki W, Shimada T, Aburada M, Masayuki, Nakano M, Selmi C , M. Eric Gershwin ME. "Monosodium glutamate (MSG): A villain and promoter of liver inflammation and dysplasia". Journal of Autoimmunity $30: 42-50.2008$.

[52] Pizarro M, Balasubramaniyan N, Solıs N, Solar A, Duarte I, Miquel J F, Suchy F J, Trauner M, Accatino L, Ananthanarayanan M, Arrese M. "Bile secretory function in the obese Zucker rat: evidence of cholestasis and altered canalicular transport function". Gut; 53:1837-18432004..

[53] Bełtowski J, Jamroz-Wisniewska A, Wójcicka G, Łowicka E, Wojtak A. "Renal antioxidant enzymes and glutathione redox status in leptin-induced hypertension". Mol Cell Biochem 319:163-174. 2008. 